\title{
Rumours as Anticipatory Knowledge in a Future Petro-State
}

\author{
By \\ Annika Witte
}

\begin{abstract}
Building on ethnographic research in Uganda, this paper discusses the mundane practice of rumourmongering and gossiping as anticipatory practices. The discovery of crude oil in Uganda brought a small oil boom to a region endowed with this natural resource, including some infrastructure development, the presence of foreign oil exploration. As these companies came into the region, so too did (young) men working for them or seeking employment. However, as the development of the oil remained in a phase of not-yet-ness, a temporal space opened up for rumours about the oil - and anyone involved with it - flourishing in the oil region. The scarce information on the (national) development of the oil project only served to intensify the rumour mill. The rumours used familiar tropes such as gender stereotypes or witchcraft in relation to the presence of foreign or at least non-local workers. Ugandans living in the oil region wondered what negative repercussions the boom might have for them and viewed the strangers with suspicion. During my fieldwork, I encountered rumours of wife-snatching, sexual harassment and even human sacrifice. This paper argues that these rumours can be understood as risk narratives or in terms of sharing of anticipatory knowledge. Looking at rumours and gossip in this way highlights the presence and relevance of anticipatory knowledge in our day-to-day lives.
\end{abstract}

Keywords: Oil, future, anticipation, rumours, risk, uncertainty

Witte, Annika: "Rumours as Anticipatory Knowledge in a Future Petro-State", Culture Unbound, Volume 13, issue 3, 2021. Published by Linköping University Electronic Press: http://www.cultureunbound.ep.liu.se 


\section{Culture Unbound}

\section{Acknowledgements}

I thank Dr. Sabine Mannitz (PRIF/HSFK) and Dr. James Thompson (MPI) for organizing this special issue and for comments and language editing on this paper. I also thank participants of the workshop "Anthropology Meets Pragmatist Philosophy" (organized by Dr. Sabine Mannitz and Dr. James Thompson), Dr. Jannik Schritt (TU Berlin), the two anonymous reviewers and the language editors from Culture Unbound for their constructive comments on earlier versions of this paper. All errors in this paper are mine. Research for this paper was funded by the Sulzmann-Stiftung, DAAD and the Institute of Social and Cultural Anthropology at the Georg-August-Universität Göttingen.

\section{Introduction}

Sitting by the side of the road in Buseruka, I was passing away the afternoon watching the noisy road construction work in front of me. The "oil road" was being upgraded to tarmac to improve the connection between Hoima and the oil wells at Lake Albert. Next to me were the grandchildren of the family I was staying with. Together we were watching the Turkish construction workers and their big machines at work. I noticed that the children watched the Turkish workers with great interest yet kept their distance. Asked why they were shy, the oldest girl, who was very outspoken, told me that their parents had warned them not to go too close to the Turks. They had heard that the Turkish workers would lure children with money, then abduct them and drink their blood or spill it on the road.

I encountered this and other rumours and gossip during my ethnographic research in Uganda's oil region from 2012 to 2015. The prospect of living in a petro-state had impacted on imagined futures of Ugandans. After discovery of oil in 2006, Uganda started preparing for its exploitation by drafting plans, policies and legislation; the country started building infrastructure and negotiating with the operating oil companies and even inviting other companies to explore for more oil. ${ }^{1}$ However, in 2021, Uganda is still becoming an oil state. If or when the oil comes as well as what societal, political and economic repercussions this would have remain uncertain. Uganda's oil is in a state of not-yet-ness, a liminal and uncertain phase in which the future is still being made (Witte 2018). The stories people tell each other about the oil and about the developments surrounding the search for oil in this not-yet-ness are part of what has been called resource-making. It refers to a social and political process by which resources are produced not only as substances but also as concepts that belong to a certain ideational system (Ferry and Limbert 2008: 4).

This paper traces imaginations of Uganda's petro-future in rumours and gossip about the negative social effects of foreign or non-local oil workers who came to 


\section{Culture Unbound}

remote parts of the country for exploration. The paper analyses these rumours and stories in terms of the sharing of anticipatory knowledge that points to risks and can create both insecurity and uncertainty. Anticipatory knowledge here refers to knowledge of the future generated through predictions, imaginations, forecasts, probability calculations, divinations or risk narratives. This knowledge is an interpretation of (assumed) facts based on theories, beliefs or even emotions such as fear or hope. ${ }^{2}$ One could go as far as saying that anticipatory knowledge tells us as much (or even more) about the present as it does about the future. With anticipation, the future finds its place in the present. It is not just temporally ahead of us, but it is among us, it is part of our present thinking, talking and acting. The future itself is a temporal space filled with hopes and dreams, fears and worries. Humans anticipate what could be; they think and talk about possibilities; they plot strategies and plans or navigate life by realising sudden opportunities, dodging misfortune and by creating contingencies (Whyte and Etyang Siu 2015, Vigh 2009).

In the following, I first present my methodology before working out the conceptual framework of this paper by discussing the concepts of rumours, risk and anticipation. Finally, I turn to a presentation and discussion of the stories and rumours I heard during my research in Uganda's oil region.

\section{Methodology}

The empirical material for this paper was gathered over the course of 15 months of multi-sited fieldwork in Uganda between 2012 and 2015. I was based in Hoima for most of my research. Labelled by some the "oil city", it was the gateway to the first oil discoveries. I also spent shorter periods of time, ranging from a few days to several weeks, in villages closer to the exploration sites. My research was based on interviews with a variety of stakeholders: small businesses, companies, village and regional politicians, national ministries, as well as civil society organisations and churches. Of course, living in the oil region and interacting with people on a daily basis brought me within earshot of the rumours and gossip people told each other about the developments surrounding the oil. Such stories are the focus of this paper and which I analyse under the framework of risk and anticipation. The next section presents the theoretical framework of this paper.

\section{Rumours, Risk and Anticipation}

Rumours are appraisive descriptions and interpretations of reality based on values and norms (Allport and Postman 1947 cit. in Stewart \& Strathern 2004: 42). People draw on their knowledge and history to interpret the present but "by doing 


\section{Culture Unbound}

Journal of Current Cultural Research

so inadvertently or purposely create the future" (Stewart \& Strathern 2004: 50). So more than just reflecting reality, rumours are constitutive of it and refresh societal values and norms (Stewart \& Strathern 2004: 40, 56). Rumours can also be seen as a tool of social criticism directed against domination (Turner 1993), or a means to control behaviour and maintain social norms (Gluckman 1963). Leon Festinger (1957) considered rumours of impending doom as unconscious rationalisations of existing fears. He built his renown theory of cognitive dissonance on this observation. This means that certain "doom" rumours can be seen as instantiations of uncertainty people experience and feel. In this sense, the rumour provides a justification for the fear after the fact.

Rumours and gossip are similar in the sense that both rely on unsubstantiated information, which can be true of false, spread by word of mouth. Furthermore, both involve a give and take of information and can catalyse social processes: Robert Paine notes that "gossip serves to pattern issues which were but vaguely or confusedly perceived by a local population" (Paine 1967: 283). The gossiper shares his/her interpretation of these issues through the gossip. Gossip and rumours differ in that rumours happen in wider networks (Stewart \& Strathern 2004: 39). Moreover, gossip is only interesting to the listeners if $s /$ he at least remotely knows the person that is the object of the gossip. When it comes to rumours, however, it is not necessary to know the person, and the source of the rumour is usually unknown and irrelevant.

Regarding witchcraft rumours, authors have noted that they actually abound in situations of massive social change and uncertainty. Famously, the Comaroffs $(2000,1993)$ connect witchcraft stories to the disruptive social effects of capitalism in Africa. Heike Behrend links cannibalism stories in Uganda to the horrors of the first wave of HIV/AIDS and to the fight against witchcraft on the part of Christian churches (Behrend, 2007, 2011). In a similar vein, Luise White (1995, 2000) shows that vampire stories in colonial Kenya flourished in a situation of tremendous social changes brought about by the colonialists. Another massive social change that caused stress and triggered stories about "soul-eaters" was the monetisation of society in Niger (Schmoll 1993). Building on Jean-Noël Kapferer, Stewart and Strathern state that "the genesis of a rumour depends on scarcity of information about an event or putative event and the anxiety that flows from such uncertainty or scarcity" (Stewart and Strathern 2004: 46). In contexts in which there is insufficient information, such as in Uganda's oil region, rumours can sow doubts and they gain a social significance.

Rumours build upon as much as further intensify uncertainty: "Equally, rumor and gossip tend to feed on and contribute to patterns of uncertainty in human communication that are intertwined with the probability of misunderstanding and conflict" (Stewart and Strathern 2004: 4). Stewart and Strathern thereby 


\section{Culture Unbound}

point to the role rumours play in the production of the future: they have the potential to influence social processes and take part in the formation of moral imaginations. Rumours and gossip work as catalysts for social processes either leading to avoidance or exacerbation of conflict (Stewart and Strathern 2004: 36). The social effects of rumours are also discussed by Bonhomme in his analysis of witchcraft rumours of "penis snatching" and "killer phone calls" as transnational genre characteristic of Africa's occult modernity.

Like many rumors of this kind, they are self-fulfilling prophecies. The frantic spread of the rumor in a particular locality creates a climate of fear, or even panic, which makes phone calls, handshakes, or alms suddenly appear suspicious to many. And this suspicion inevitably triggers incidents, which by a sort of snowball effect, impart new vigor to the rumor's circulation. (Bonhomme 2012:209)

In other words, these rumours create uncertainty and insecurity, but the source of harm is so broad and vague (like a handshake that ends up shrinking a penis) that prevention becomes difficult. Rumours and gossip can thus catalyse social processes leading to uncertainty and insecurity, e.g., when they trigger mob justice (Allen 2015).

Although uncertainty and insecurity are often used interchangeably, they need to be distinguished from one another. Whyte (2009: 213) distinguishes the two as follows: uncertainty is a state of mind and insecurity is a social condition that refers to a lack of protection and weak social networks that provide no safety in the face of adversity. Uncertainty means a radical questioning of what reality is (Calkins 2016). It means unpredictability, instability, lack of (accurate) knowledge, unreliability and the difficulty to interpret or even fathom life (De Boeck 2012: 200). It can be described as, "we know that we do not know, but that is almost all that we know" (Callon et al. 2011: 21). Uncertainty is not a condition inherent to a situation, but rather it is a question of perception. Someone needs to raise the question of whether reality is really what it appears to be. This is particularly the case with witchcraft rumours. For doubt about reality to arise, a good and at least somewhat believable story from a neighbour or friend can be enough. Witchcraft rumours, in particular, identify a potential harm; however, the means to manage it are less than certain. Rumours contain too little information for informed guesses; they transform uncertainty into potentialities - not into certainty.

Rumours and gossip discussed in this paper highlight a harm that is threatening a valued object or category of persons. This identification of a source of harm as well as the attachment of value are essential parts of a risk narrative according to a relational or social constructivist understanding of risk: the elements of a risk narrative are the 


\section{Culture Unbound}

risk object, the object at risk and the relation between the two (Boholm \& Corvellec 2011, Hilgartner 1992). Generally, the social constructivist definition of risk differs from the common view that sees risks as probability calculations or damages that can be predicted with numbers. It instead emphasises that risks are socially constructed through (scientific) reports that single out harmful agents or through stories people tell each other about the dangers that surround them - sometimes but not always corroborated by numbers. Hilgartner (1992: 51-52) argues that risks are only constructed by risk experts who scientifically establish them. My understanding of risk construction differs from Hilgartner's with regard to the laymen's role in risk construction. In my understanding, risk narratives are also stories people tell each other about potential harm. In this perspective, risks are not an objective category but something that is created subjectively and in interaction with others.

Risks have been called the anticipation of catastrophe (Beck 1986). Anticipation includes discourses, practices, technologies and material devices that bring the future into the present (Weszkalnys 2014). Anticipation means expecting or predicting something and acting on or talking about it. Risks offer a way of anticipating possibilities and thereby to manage or even profit off uncertainty by predicting the future. Risks can thus be seen as a form of anticipatory knowledge. Therefore, the way we construct risks - i.e., the risk narratives - also belong to anticipatory knowledge. As noted above, at times risk narratives are contained in rumours that connect risk objects to objects at risk. Hence, rumours can also be understood as anticipatory knowledge even though this might seem counterintuitive, because rumours are about events that happened in the past. As research has shown, however, rumours don't just describe past events but also deliver interpretations of them that at times have a predictive character. Moreover, rumours - just like risks - have the potential to change how the listener perceives reality and acts in it.

Risks can transform uncertainty so that they offer the illusion of certainty. When it comes to risk, we know the groups who are at risk, we know the events that could take place, their causes and their possibilities, while with uncertainty we don't (Callon et al. 2011: 20-21). As Hilgartner pointed out, we know about the causes through a selection process. One cause gets singled out from many other possible causes, and the chain of causes stops at a certain point. This point is particularly important and warrants attention (Hilgartner 1992: 42). Mary Douglas famously argues that risks are essentially cultural, and that the perception of risks is connected to the norms and values of a culture (Douglas 1992, Douglas \& Wildavsky 1983). While I do not agree with this culturalist perspective, the connection it makes between risks and values is nonetheless worth noting, for I understand risks to reflect values and norms - as categories open to negotiation and change, not as static cultural categories. 


\section{Culture Unbound}

Risks are like binoculars: they make something far away appear close and within our reach - in this case, a temporal distance. With risks the future becomes palpable. We anticipate it and even shape the future, as the acknowledgement of risks can reflect back on present behaviour. This paper analyses rumours as risk narratives and thereby adds to an understanding of everyday anticipatory knowledge. It moves the discussion of anticipation to very mundane aspects of life that are a far cry from sophisticated forecasting tools and probability calculations.

In the following section, I will discuss some of the rumours that I encountered in Uganda's oil region during my research. I see the rumours discussed in this paper connected to the uncertainty that was prevalent in the oil region. The rumours draw on familiar tropes involving gender norms and witchcraft.

\section{Rumours in the Oil Region}

Uganda's oil region spans several districts around Lake Albert in Western Uganda and West Nile in the North-West of the country. A common feature of the districts where oil was discovered was a predominance of (smallholder) agriculture as the main economic activity, relative poverty and a more marginalised position vis-à-vis the nation state. Hoima, the oil city and slow-paced capital of the formerly great kingdom of Bunyoro, had the reputation of a backwater place. The fishing communities on the shores of Lake Albert were difficult to reach before they were connected via the improved road network to the rest of Uganda as a consequence of oil production. In the 1990s, Bunyoro had a high poverty rate, one comparable to the war-ravaged Northern Uganda (Kiiza et al 2013: 11). While the rate went down considerably, still more than a third of Bunyoro's population was living in poverty in 2016 (UNICEF 2020: 7). The oil districts in West Nile fared even worse with more than three quarters of the population living in multidimensional poverty (UNICEF 2020: 7, 10).

The not-yet-ness of Uganda's oil meant an extended temporal space for rumours about the oil and anyone involved with it to flourish. Ugandans living in the oil region not only wondered about whether they would profit from the oil but also worried if it might have negative repercussions for them. While I had heard rumours that people thought they could tap free-flowing oil at the wells in jerry cans, I found many to be sceptical about the glorious petro-future the government and the oil companies proclaimed.

For one, sound knowledge about the oil project was scarce. Farmers, fishermen and politicians of villages situated in exploration areas expressed their lack of knowledge about the oil and were worried it might affect their livelihoods. Fishermen feared losing their right to fish or having to leave the area altogether, while farmers thought they might lose their land and livelihood. Relocation was a 


\section{Culture Unbound}

major fear and was related to experiences made during the exploration activities and the construction of a new road. In a school essay competition organised by an NGO in Hoima, the overall top three expectations were work, roads and resettlements - an ambivalent mix of positive and negative expectations. People did not just fear the changes but also looked forward to a better overall standard of living, including schools, hospitals, better transport, a market for local produce and an industrialisation of the region.

Another reason for scepticism was that the oil discovery had brought new tensions to the oil region: conflicts about land and the adequate compensation, the destruction of crops, property or cultural sites during oil exploration, and an increasing number of (young) men from other parts of Uganda or even other countries. This increase in migrant labour was remarked on even though the region had seen migration before. As the oil region borders the Democratic Republic of Congo, it has hosted hundreds of thousands of Congolese refugees. Also, internal migration to the region has existed before the oil discovery, e.g., Balaalo cattle keepers on transhumance. Yet it was only after the discovery of oil that their presence became contentious (Kinyera \& Doevenspeck 2019: 9). A recurring complaint in interviews and conferences organised by civil society was about the sudden increase in population that usually accompanies resource booms. This population increase was viewed critically since it meant an influx of foreigners. People feared these foreigners would bring their own "cultural practices' that might challenge the local or "traditional" ones, especially if they married locals. I often heard complaints that young (and mainly non-local) men who got a job in the oil industry were spending their salaries in bars and on local women. In this paper, I focus on these negative expectations connected with the population increase and above all the presence of foreign men in the region.

In 2013, I stayed for several weeks in Pakwach, a small town in West Nile on the banks of River Nile. While there, I discussed the impacts of the arrival of oil workers with a Ugandan volunteer for a local NGO. He told me how elders in Panyimur, a close-by fishing village on the northern shore of Lake Albert, had complained to him that the women only liked to be with the (foreign) oil workers and not with the local men anymore. The elders were worried that the women (and the young men) would not marry anymore, eventually leading to a breakdown of social structures. These elder men interpreted the impact of these changes on the future: if girls were no longer interested in the local boys, social structures would invariably change. This was only compounded by claims that the oil workers had no regard for a woman's marital status or age.

Rumours of oil workers taking young women or even other men's women abounded. Reportedly, this led to several cases of broken-up marriages. One local politician in Pakwach told me how this happened to both his son and daughter. 


\section{Culture Unbound}

Journal of Current Cultural Research

He confided in me that one oil worker impregnated his school-going daughter, and his son's wife was caught with an oil worker at one of the lodges in town. $\mathrm{He}$ explained that the oil workers spoilt the young girls by spending money on them.

Another resident of Pakwach and former casual worker I talked to was determined about not letting his wife work for an oil company because he feared the boss could harass or charm her:

These guys have the money but they don't mind. [...] The situation guys have brought on is alarming, immorality talking. Marriages are breaking up. They have gone as far as snatching settled wives (Former casual worker, interview, 2013).

While conducting interviews in Pakwach, several people told me stories about oil workers sleeping with underage girls, spreading HIV or impregnating them. A Ugandan casual worker for a subcontractor saw these women dating oil workers as "stupid villagers" for believing the workers were interested in more than just sex. Yet the workers considered them only as their "by the ways".

From a female perspective, the situation was much more complex. In a focus group discussion, women from Pakwach did mention that some women or girls got taken advantage of, but that others consciously chose to go with the oil workers as they needed the money they gave. All women were concerned though about the effects these promiscuous oil workers had on the HIV/Aids infection rate in town, referring to Pakwach as being "dead" already. Some of the women were bitter that the only employment opportunity the oil had brought them was prostitution. Indeed, women in Uganda, including in the oil region, were disfavoured in terms of access to education, wage labour and resources such as land (see e.g., International Alert 2014, UNFPA 2017).

Women and girls from the surrounding villages came to Pakwach on market day and then simply stayed on instead of going back home. The community development officer of Pakwach explained that these girls hoped to find a man or customers. Pakwach has had prostitution before the oil boom as many truck drivers coming from Kenya or Congo stopped here on their journeys. However, she told me the situation had worsened when the oil activities started and many young men moved into the area.

The complaints about oil workers were not just common in Pakwach but also in other parts of the oil region. During my research stay in 2012/2013, the construction of a road between Hoima and Kaiso-Tonya, a village close to future oil production sites, was underway as mentioned in the introductory vignette. The Turkish construction company had brought Turks to do the job. While normally housed in a camp, on their days off they would flock to Hoima town to enjoy 


\section{Culture Unbound}

what leisure it had to offer. Gossip about the Turkish men and their chauvinistic or sexist behaviour were flying around. People were annoyed by how the Turkish men treated their women: sleeping with many women and with prostitutes and sexually harassing female casual workers at work.

While the construction on Kaiso Road was in full swing, I stayed for a couple of weeks with a family of a former politician residing along the road. During this time, I witnessed one particular interaction between the Turkish and local workers. Sitting by the side of the road, I saw a middle-aged Turkish worker teasing and touching a young female co-worker's buttocks and breasts while she was laughing and teasing him back. I could not tell whether she was uncomfortable or not. I must have had a surprised look on my face, for she walked up to me and explained that they were just joking and then walked back to the man. Clearly, these rumours are not entirely unsubstantiated. They do reflect some part of reality - but under a particular prism. They interpret social reality based on stereotypes about women and strangers, in this case the Turkish manual labourers. ${ }^{3}$

The rumours can be interpreted as reflecting the unsettling effect the arrival of wealthier men, deemed to be more attractive to local women, had on many local men. This is not the only case of strangers attracting local women, as Bourdieu shows in his analysis of detrimental social change in his home region with the arrival of stylish and eloquent visitors from the city, who impressed the rural ladies more than the resident farmers (Bourdieu 2007). Using Gluckman (1963), it is possible to argue that the function of the rumour was to control behaviour and to shield women from both the dangers (but also the opportunities) that came with these new men. Yet, I see little evidence for this regulatory function of risk. If intended as regulatory devices, they failed as women still went out with oil workers.

However, the functional argument is also familiar from Mary Douglas' analysis of risk. She compares risks to taboos: they both create connections between actions and harm and influence or regulate (future) behaviour (Douglas 1992: 26-7). According to Douglas, the important question is always: who is accorded the blame if something goes wrong? (Douglas 1992) This cultural or relativistic theory of risk has been criticised for being neither based on empirical data nor substantiated later by empirical studies (Boholm 2015: 58). However, asking the simple but powerful question of who is accorded the blame is still an important part of analysing risks.

The rumours related not only to how (foreign) oil workers posed a risk to society, e.g., breaking up families, but also how they were a risk for women who were exposed to their charms and/or aggressions. What was expected to go wrong, then, was the destruction of family structures - and the social fabric, no less with the existing culture being lost to a new mélange of cultures. Something of value, that is, the family as well as daughters or wives, had come under threat. And 


\section{Culture Unbound}

who was to blame? It was the strangers that came to the region working for the oil companies (and its subcontractors). The threat stemmed from an outside agent the oil worker. All elements of a risk narrative, i.e., the risk object, the object at risk and the causal narrative, can be found in these rumours (Boholm and Corvellec 2011; Hilgartner 1992).

These rumours can be seen as a warning to both men and women of the potential harm that can come from close interactions with the oil workers. The rumours were told in anticipation of continuing negative experiences by local women and potential adverse effects on local culture and the general social setting. The rumours reflect values the rumourmongers gave to family or, more generally, the current social structure. These values speak to prevalent gender norms that see men as the provider, decision-maker and head of the family.

In all the rumours, if viewed as decision-makers, women were considered too stupid for their own good, or they were reduced to mere objects of male desire (from which they had to be protected). The risk object in turn was "male strangers". These were the men that stole wives, deceived young girls and abused women. Not surprisingly, in a society with dominant patriarchal values, this is a very male-centred perspective on the topic. Needless to say, some women might have done a good job of calculating the risks and the gains they stood to make. ${ }^{4}$ Also, romance and finance are connected in intricate ways, and money flows in relationships can also foster sexual identities for both men and women (Mills \& Ssewakiryanga 2004).

Finally, let us consider another, more chilling rumour in detail that I described in the introductory vignette. It depicted Turkish construction workers, who built the abovementioned Kaiso Road, as some kind of vampires. Asked about it later, the children's grandfather, a former local politician whose family I was staying with for a couple of weeks, confirmed that these stories circulated, but he said they were just the imagination of people. The Turkish men only sacrificed goats - not humans - for the road.

This story connected the Turks to ritual murder, i.e. witchcraft, or cannibalism. Strangers, or in fact strange men (here in the double sense of the word), were once again the risk object, while this time the object at risk was a category of persons generally perceived to be less able to protect themselves: children. The rumours of vampires are similar to the "lionmen" stories that circulated in Chad, in which Exxon oil workers were eaten by lionmen (Reyna 2011). Reyna argues that this story gave people in the Doba Basin the opportunity to voice their fears connected with the arrival of the oil industry. The stories sow distrust and encourage resistance against imperial domination. The rumours I discuss here can also be seen as a kind of subaltern resistance against domination by foreign actors or, more specifically, if we take a longue durée perspective, against long-lasting 


\section{Culture Unbound}

Journal of Current Cultural Research

unequal power relations between (white) foreigners and local men. While this perspective focuses on the present grievances, I would add that the rumours in the oil region can also be seen as resistance against a feared continued future domination by foreigners up to the complete erasure of "traditional" culture by foreign cultures.

Building on the studies mentioned in the theoretical framework, I suggest the stories of blood-drinking construction workers are an instantiation of the uncertainty people in the oil region felt. The rumours can be viewed as reactions to the massive changes that suddenly arrived: big machines ploughing through the landscape driven by foreigners who do not even speak a familiar language. These rumours show a level of distrust towards foreigners who came to the oil region and from whom children and women were best kept away. As the grandchildren themselves had pointed out, their parents had used the rumours to warn them and tried to control their behaviour.

The trope of the dangerous stranger is a familiar one in witchcraft rumours, as Bonhomme points out:

As we will see, rumors of penis snatching, of killer phone numbers, and of deadly alms all revolve around anonymous interactions that turn out to be fatal. These new forms of the occult focus on the dangers of anonymity, which is precisely an interactional repertoire typical, and even constitutive, of modernity (Bonhomme 2012: 211-212).

A trope of these witchcraft rumours is thus the dangerous stranger. Unlike "classic" forms of witchcraft, the new risks do not spring from intimacy and the family but from anonymity and strangers (Bonhomme 2012: 225). Bonhomme sees such rumours as "a sense of exposure and vulnerability to occult forces, which relates to other dimensions of insecurity in everyday life" (Bonhomme 2012: 226). And the strangeness, as in this case, is the unknown and uncertain.

The occult rumours thrive in a climate of mistrust and suspicion as well as situations where people are forced to interact with strangers. While the rumours Bonhomme writes about are situated in the urban context, the sudden influx of many strangers to a rural area due to oil exploration activities might just as well be such a situation of unavoidable interactions with strangers. The occult rumours turn these interactions into mortal dangers (Bonhomme 2012: 226). The spread of rumours in the oil region also follows the trope of strangeness. Drawing on familiar tropes such as strangeness, or basing the causal argument on widespread gender stereotypes, makes the risk believable even without scientific evidence. These rumours were not only reactions by the locals to new uncertainties but also anticipations of possible negative outcomes for themselves and their society. 


\section{Culture Unbound}

Spreading the rumours can be understood as sharing anticipatory knowledge. It makes others aware of perceived risks they might not have heard about or realised otherwise. Rumourmongering might seem too simple an act and too mundane a practice to consider them risk narratives or anticipation. Yet, it is precisely these mundane sources that inform a lot of our day-to-day behaviour and judgement. Furthermore, analyses of witchcraft rumours have demonstrated how they can easily escalate from story to self-fulfilling prophecy. Witchcraft rumours have an explosive potential and have often led to violence and mob justice, thereby contributing to and creating insecurity. Yet, the intention of telling the story and pointing out a risk might have only been to keep the listener safe from a perceived harm. ${ }^{5}$ Risks and security are thus double-edged swords, and above all in situations of uncertainty, such as in the oil region, insecurity is just a rumour away.

\section{Conclusion}

In this paper, I have argued that rumours can be seen as anticipatory knowledge. The rumours I presented here pointed out risks in a climate of uncertainty. Risks are not just probability calculations but are also stories about potential harm that people tell each other based on their own (or someone else's) experience. These stories don't have to be elaborate, yet the elements of risk narratives can be found in mundane gossip and rumours. The rumours I analysed in this paper were circulating in Uganda's oil region after the discovery of oil and during ongoing exploration activities. The stories emerged in a moment of not-yet-ness filled with social changes and uncertainty. The rumours were about sexual relations foreign or non-local oil workers had with local women and girls. Other rumours attributed cannibalistic practices to some of these strangers. The rumours were risk narratives that depicted the family as a social unit and women and children as individuals at risk of being harmed by the strangers. The (witchcraft) rumours drew on familiar tropes, such as strangeness and gender stereotypes, as causal arguments, rendering them believable to the listener. While partially based on real experiences, the rumours were more than reflections of the past: they were told in anticipation of the dark side of the future. This paper suggests that anticipatory knowledge can be discovered even in the mundane acts of gossiping and rumourmongering. While far from informed predictions or forecasts, such risk-rumours are highly relevant in the way they can shape the perceptions, expectations and even actions of those who hear them. 


\section{Culture Unbound}

\section{Author}

Annika Witte, University of Göttingen, annika_witte@icloud.com

Annika Witte is a social anthropologist interested in oil, risk, uncertainty and temporality as well as urban agriculture with a particular focus on agrochemicals. She has conducted research in Uganda, Cameroon and Benin. For several years, she worked as a lecturer and researcher at the Institute of Social and Cultural Anthropology at the University of Göttingen. She currently works in Cameroon.

\section{References}

Allen, Tim (2015): "Vigilantes, Witches and Vampires: How Moral Populism Shapes Social Accountability in Northern Uganda," International Journal on Minority and Group Rights, 22, 360-386.

Beck, Ulrich (1986): Risikogesellschaft: Auf Dem Weg in Eine Andere Moderne. Berlin: Suhrkamp.

Behrend, Heike (2011): Resurrecting Cannibals: The Catholic Church, WitchHunts and the Production of Pagans in Western Uganda. Woodbridge: Currey. ---- (2007): "The Rise of Occult Powers, AIDS and the Roman Catholic Church in Western Uganda," Journal of Religion in Africa, 37:1, 41-58.

Boholm, Asa (2015): Anthropology and Risk. London: Routledge.

Boholm, Åsa, \& Hervé Corvellec (2011): "A Relational Theory of Risk," Journal of Risk Research, 14:2, 175-90.

Bonhomme, Julien (2012): "The dangers of anonymity: Witchcraft, rumor, and modernity in Africa." HAU: Journal of Ethnographic Theory 2:2, 205-233.

Bourdieu, Pierre (2007): The Bachelors' Ball: The Crisis of Peasant Society in Béarn. Chicago: University of Chicago Press.

Callon, Michel; Lascoumes, Pierre \& Yannick Barthe (2011): Acting in an Uncertain World: An Essay on Technical Democracy. Cambridge, MA: MIT Press.

Comaroff, John \& Jean Comaroff (2000). "Millennial Capitalism: First Thoughts on a Second Coming," Public Culture, 12:2, 291-343. ----- (eds): (1993): Modernity and its Malcontents: Ritual and Power in Postcolonial Africa. Chicago: Chicago University Press.

De Boeck, Filip (2012): "Kinshasa and its (Un)Certainties: The Polis and the Sacred," Gómez, Liliana \& Walter van Herck (eds): The Sacred in the City, London: Continuum, 191-207.

Douglas, Mary. 1992. Risk and Blame: Essays in Cultural Theory. London: Routledge.

Douglas, Mary and Aaron Wildavsky. 1983. Risk and Culture: An Essay on the Selection of Technical and Environmental Dangers. Berkeley: University of California Press. 


\section{Culture Unbound}

Ferry, Elizabeth \& Mandana E. Limbert (2008): “Introduction,” Ferry, Elizabeth E. \& Mandana E. Limbert (eds): Timely Assets: The Politics of Resources and Their Temporalities, Santa Fe: School for Advanced Research Press, 3-24.

Festinger, Leon (1957): A Theory of Cognitive Dissonance. Stanford: Stanford University Press.

Gluckman, Max (1963): “Gossip and Scandal,” Current Anthropology, 4:3, 307- 316.

Hilgartner, Stephen (1992): "The Social Construction of Risk Objects Or, How to Pry Open Networks of Risk," Short, James F Jr. \& Lee Clarke (eds): Organizations, Uncertainties, and Risk, Boulder: Westview Press, 39-53.

Homaifar, Nazaneen (2008): “The African Prostitute: An Everyday "Debrouillard" in Reality and African Fiction," Journal of African Cultural Studies, 20:2, 173-182.

International Alert (2014): What's in it for Us? Gender Issues in Uganda's Oil and Gas Sector. London: International Alert. Available online: https://www.international-alert.org/sites/default/files/Uganda_GenderOilGas_EN_2014.pdf [last accessed 30th May 2021].

Kiiza, Julius, Bategeka, Lawrence, \& Sarah Ssewanyana (2013): Oil Discovery in Uganda: Managing Expectations, Working Paper Economic Policy Research Centre, Makerere University.

Kinyera, Paddy \& Martin Doevenspeck (2019): Imagined futures, mobility and the making of oil conflicts in Uganda. Journal of Eastern African Studies, 13, 3: 389-408.

Mills, David \& Richard Ssewakiryanga (2004): "No Romance Without Finance: Commodities, Masculinities and Relationships Amongst Kampalan Students," Cornwall, Andrea (ed.), Readings in Gender in Africa, Oxford: James Currey, 90-95.

Paine, Robert (1967): What is Gossip About? An Alternative Hypothesis. Man, New Series, 2: 2, 278-285.

Reyna, Stephen (2011): "Constituting Domination/Constructing Monsters: Imperialism, Cultural Desire, and Anti-Beowulfs in the Chadian Petro-State," Behrends, Andrea, Reyna, Stephen \& Günther Schlee (eds): Crude Domination: An Anthropology of Oil, Oxford: Berghahn, 132-162.

Sadgrove, Jo (2007): "Keeping Up Appearances": Sex and Religion Amongst University Students in Uganda," Journal of Religion in Africa, 37:1, 116-144.

Samara, Suesanne (2010): "Something-for-Something Love: The Motivations of Young Women in Uganda," Journal of Health Organization and Management 24:5, 512-519.

Schmoll, Pamela (1993): "Black Stomachs, Beautiful Stones: Soul-Eating Among Hausa in Niger," Comaroff, Jean \& John Comaroff (eds): Modernity and its Malcontents. Chicago: Chicago University Press, 193-220. 


\section{Culture Unbound}

Journal of Current Cultural Research

Stewart, Pamela J. \& Andrew Strathern (2004): Witchcraft, Sorcery, Rumours, and

Gossip. Cambridge: Cambridge University Press.

Turner, Patricia (1993): I heard it through the grapevine: Rumor in Africa-American Culture. Berkeley: University of California Press.

Vigh, Henrik (2009): "Motion Squared: A Second Look at the Concept of Social Navigation," Anthropological Theory 9:4, 419-438.

UNICEF (2020): Uganda's Multidimensional Poverty Profile: Going Beyond Monetary Poverty. Kampala: UNICEF Uganda.

UNFPA (2017): Worlds apart in Uganda: Inequalities in Women's Health, Education and Economic Empowerment. Population Matters Policy Brief, 5.

Weszkalnys, Gisa (2014): "Anticipating oil: the temporal politics of a disaster yet to come," The Sociological Review, 62(SUPPL1), 211-235.

White, Luise (2000): Speaking with Vampires: Rumor and History in Colonial Africa. Berkeley: University of California Press.

Whyte, Susan Reynolds \& Godfrey Etyang Siu (2015): "Contingency: Interpersonal and Historical Dependencies in HIV Care," Cooper, Elizabeth \& David Pratten (eds): Ethnographies of Uncertainty in Africa, Basingstoke: Palgrave Macmillan, 19-35.

Whyte, Susan Reynolds (2009): "Epilogue," Haram, Liv \& C. Bawa Yamba (eds): Dealing with Uncertainty in Contemporary African Lives, Nordiska Afrikainstitutet:

GML Print on demand, 213-216.

Witte, Annika. 2018. An Uncertain Future - Anticipating Oil in Uganda. Göttingen: Göttingen University Press.

\footnotetext{
${ }^{1}$ There are three oil companies currently operating as a joint venture in Uganda: the multinational Total E\&P Uganda Ltd, the Chinese multinational Chinese National Offshore Oil Corporation (CNOOC), and the Irish independent company Tullow Oil Uganda Ltd. Since 2017, Tullow Oil has become a non-active partner in the business.

${ }^{2}$ In this paper, I am not concerned with the truthfulness or accurateness of these predictions or of the underlying facts. My focus is on the ways in which these rumours themselves can impact the future irrespective of their factual correctness.

${ }^{3}$ These rumours are of course generalisations that do not capture the diversity and difference among the Turkish workers. The rumours are reproduced in this text for sake of analysis.

${ }^{4}$ See research on prostitution as a form debrouillardise (Homaifar 2008), or on "detoothing" in Uganda, in which a woman uses her sexuality or the promise of sex to extract money and gifts from a man (Sadgrove, 2007). Also, motivations to be part of "something-for-something-love' are diverse and complex and by no means stupid at all (Samara, 2010).

${ }^{5}$ Of course, one should not view these rumours as entirely detached from their sensational and entertainment value. They also make for a good and chilling story - a story likely to be shared with more people for this very reason.
} 